\title{
OBRA SOBRE TRADUÇÃO TÉCNICA E CIENTÍFICA DE OLOHAN CONTRIBUI SOBREMANEIRA PARA DIFUNDIR O USO DA LÍNGUÍSTICA DE CORPUS NO ESTUDO E NA PRÁTICA DA TRADUÇÃO ESPECIALIZADA
}

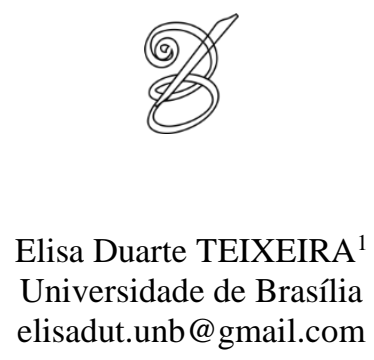

tradução especializada parece estar, aos poucos, deixando de ser o patinho feio dos
Estudos da Tradução, ainda que esteja longe de exibir a plumagem resplandecente
dos cisnes, pelo menos no que toca à representatividade junto à produção acadêmica da área. O livro Scientific and Technical Translation, de Maeve Olohan, lançado no ano passado pela Routledge, faz parte da coleção Routledge Translation Guides, que conta apenas com mais um título até o momento, Literary Translation (WRIGHT, 2016). A obra vem somar-se aos raros livros que se dedicam especificamente à tradução técnica, tais como Pinchuck (1977), Azenha Júnior (1999), Kingscott (2002), Byrne (2006, 2012) e Rogers (2015), ou que combinam Tradução Técnica, Terminologia e Linguística de Corpus, como Pearson (1998) e Bowker \& Pearson (2002), por exemplo.

Maeve Olohan, Senior Lecturer da Universidade de Manchester, no Reino Unido, tem publicado extensivamente sobre o tema desde 1993, e é de sua autoria um dos primeiros livros a tratar a fundo do uso de corpora nos estudos da tradução: Introducing Corpora in Translation Studies, lançado em 2004, também pela Routledge. À época, Olohan era uma das únicas autoras, além de Mona Baker, a chamar de corpus comparável um conjunto de textos traduzidos para uma dada língua de chegada, partindo de originais em quaisquer línguas, acompanhado de outro conjunto de textos com características “comparáveis”, mas produzidos originalmente na tal língua de chegada. O objetivo da comparação era identificar os chamados "universais da tradução" - características linguísticas do texto traduzido que independem da língua de partida do original (Baker, 1993, p. 243). 
Nos quase 25 anos que se passaram desde que Baker acenou para o uso de corpora nos estudos da tradução, muita coisa aconteceu, tanto na prática da tradução quanto na reflexão sobre essa prática e seu ensino. E um dos avanços mais benfazejos e significativos das últimas décadas é, justamente, a importância maior que se passou a dar à tradução de textos especializados. Afinal, eles representam a maior fatia do mercado de tradução - cerca de 90\%, na estimativa de Kingscott (2002, p. 247) - e são, portanto, o tipo de texto com que a grande maioria dos alunos egressos de cursos de tradução de diferentes níveis de especialização vai passar a trabalhar após se formar. Com Scientific and Technical Translation, Olohan contribui sobremaneira para, por um lado, reafirmar a tradução técnica e científica como objeto de estudo acadêmico e, por outro, colocar a tradução especializada, seu ensino e sua praxis no centro das atenções de tradutores aprendizes, professores e pesquisadores que se debruçam sobre essa modalidade da tradução.

As 254 páginas da obra são divididas em sete capítulos: dois mais gerais e introdutórios, "Scientific and technical translation as professional activity" e "Resources for scientific and technical translation"; e outros cinco dedicados a gêneros e tipologias textuais específicos das linguagens especializadas, a saber, "Technical instructions", "Technical data sheets and technical brochures", "Patents", "Scientific research articles and abstracts" e "Popular science". O livro conta ainda com um breve glossário, que inclui termos de áreas como a Línguística de Corpus (como colligation, concordance, n-gram, semantic prosody), a Terminologia e a Lexicologia (p. ex. concept, generic relation, terminology management, term bank, phraseology), entre outros, um sumário, listas de tabelas e abreviações, uma introdução, cinco anexos e, nas páginas finais, um índice remissivo.

Pensado como material de apoio para uma disciplina de tradução técnica de um mestrado (ou graduação) em tradução, ou para tradutores autodidatas, o livro pressupõe um conhecimento básico prévio sobre a área e/ou alguma prática anterior em tradução técnica. Uma apresentação bem didática e sistemática estrutura todos os capítulos, que começam sempre com um breve resumo, de cerca de dez linhas, apresentando as temáticas que serão tratadas naquela seção do texto, e terminam com uma série de exercícios práticos, um quadroresumo listando os principais pontos discutidos, e a bibliografia usada para desenvolver os temas contemplados. Os excertos menores, usados para exemplificar e ilustrar os fundamentos teóricos apresentados, são destacados do corpo do texto por meio do uso de uma moldura, facilitando sua localização, e os mais longos foram transformados em anexos. A obra também 
está repleta de links para sites da Internet em que o aprendiz poderá encontrar outros recursos e materiais de referência úteis ao seu aprendizado e à sua prática futura.

Na Introdução, a autora nos conta um pouco sobre sua motivação para escrever o livro, explicitando o público-alvo a que a obra se destina e estabelecendo os principais resultados de aprendizagem esperados: compreender as situações de comunicação especializadas; reconhecer o propósito retórico e discursivo de textos técnicos e científicos; entender como operam os tradutores técnicos das diversas áreas; analisar textos usando conceitos e a metalinguagem dos estudos da tradução e de áreas correlatas; aplicar vários recursos de auxílio à prática tradutória; produzir traduções técnicas e científicas e ser capaz de defender suas escolhas tradutórias; e avaliar sua própria tradução e a de colegas de profissão. Para a autora, é importante que os tradutores técnicos" "se tornem profissionais pensantes, capazes de agir com responsabilidade perante seus clientes, usar conhecimento especializado e praticar o pensamento e a apreciação independentes" (p. 4, tradução nossa), além de aprenderem a trabalhar colaborativamente em equipes e a desenvolverem suas habilidades interpessoais.

O primeiro capítulo introduz a modalidade especializada da tradução ao leitor discutindo, primeiramente, a diferença entre textos técnicos e científicos. Olohan ressalta que, ao contrário do que parece, a ciência não é imparcial, objetiva ou neutra - é uma atividade condicionada cultural e socialmente como todas as demais e, por isso, pode ter por trás motivações ideológicas e políticas que não podem ser desprezadas pelo tradutor. Em seguida, a autora faz um panorama do mercado de trabalho, descrevendo vários cenários profissionais que encontram equivalentes também em nossa cultura, por exemplo: empresas de tradução que contratam tradutores assalariados ou freelance, empresas que não são de tradução mas têm um departamento dedicado a esta atividade, e empregam tradutores assalariados ou freelance, organizações internacionais e governamentais que empregam tradutores assalariados ou freelance. Ela menciona também outras funções que o tradutor pode desempenhar na indústria, tais como gerente de projeto de tradução, terminólogo, revisor ou editor. Muitas dessas funções requerem um conhecimento especializado mais aprofundado, tanto da área especializada em si quanto dos meandros técnicos e teóricos envolvidos. O ponto central do capítulo é explanação e discussão dos propósitos comunicativos e dos agentes envolvidos na comunicação especializada, que são um preâmbulo para a apresentação 
do briefing de tradução, adaptado do que foi proposto pela British Standard Institution (p. 2021).

O segundo capítulo a autora dedica aos recursos de apoio à tradução, dando destaque especial à Terminologia e, mais especificamente, à Terminologia Baseada em Corpus (Corpus-based Terminolgy). Após apresentar um breve apanhado dos conceitos básicos dessas duas áreas correlatas e de defender sua utilidade para a tradução técnica, Olohan descreve brevemente as etapas envolvidas na compilação, exploração e uso de corpora para solucionar problemas de tradução e terminologia, mostrando vários exemplos de tela da ferramenta Sketch Engine (KILGARRIFF et al, 2014). A identificação de termos e outras unidades de tradução recorrentes em corpora, bem como seu armazenamento e manutenção merecem seções distintas no texto, que destaca, na sequência, a utilidade de memórias de tradução e da tradução automática na atividade tradutória de textos técnicos e científicos.

Nos cinco capítulos seguintes, a autora trata de gêneros recorrentes da tradução especializada. O capítulo 3, sobre instruções técnicas, aborda temas como usabilidade, legibilidade, importância das imagens para textos instrucionais, além de apresentar algumas 180 características específicas desse tipo de texto, usando vários excertos de um manual de máquina de pão para ilustrar os pontos discutidos.

No capítulo 4, sobre especificações técnicas e catálogos técnicos de produtos, o destaque vai para os aspectos comerciais desse tipo de texto, envolvendo identidade de marca, aspectos gráficos e apelo promocional. Também são discutidos dados técnicos, como sistemas de medidas, padrões de qualidade, certificações e leis regulamentares, abreviações e terminologia específica do gênero. Por fim, a autora contrasta esses dois tipos de documento e dá vários exemplos de tradução relacionados, em diversas línguas.

O capítulo 5 é dedicado às patentes, e o tipo textual escolhido como representativo desse gênero é o documento de solicitação de registro de patente. Após uma breve introdução aos aspectos legais e culturais das patentes, que vão variar de país a país, a autora descreve as características textuais desse tipo de documento em detalhe, apresentando vários exemplos. Fornece uma lista comentada dos escritórios nacionais regionais de registro de patentes, abordando também a tentativa de se criarem escritórios para funcionarem como órgãos internacionais de monitoração de patentes e que influência isso tem na tradução desse tipo de documento. 
O sexto e sétimo capítulos tratam da tradução de textos científicos e ocupam quase um terço do livro. Enquanto o primeiro aborda textos produzidos por especialistas para serem lidos por especialistas, o último é sobre divulgação, ou popularização de ciência.

Um dos pontos altos do sexto capítulo, a meu ver, é a discussão que a autora faz sobre as consequências de o inglês ter se tornado a língua franca da ciência, e sobre como essa pasteurização da divulgação da produção do conhecimento promove um achatamento e um apagamento das diferenças epistemológicas existentes entre as tradições culturais e acadêmicas, condicionadas a se expressarem e produzirem conhecimento em língua inglesa fenômeno que Swales (1997) chamou de "epistemicídio". Olohan dá especial atenção às características que tipificam os textos científicos quanto ao léxico especializado que circulam (vocabulário acadêmico e pacotes lexicais - lexical bundles) e à organização e construção da argumentação por meio de movimentos retóricos típicos. Destaca também a importância do metadiscurso e das metáforas na comunicação científica, dedica uma seção inteira à tradução de resumos, e finaliza o capítulo com considerações acerca das particularidades de se traduzir em três pares específicos de línguas (contendo o inglês): francês, espanhol e chinês.

No capítulo 7, os aspectos mais notórios do discurso de popularização da ciência são esboçados. A autora dá vários exemplos de como esse tipo de discurso pode assumir diversas formas e níveis de especialização, e circular em meios de comunicação variados. Olohan dá destaque especial à importância da tradução do título e do olho das matérias. Outros aspectos que podem trazer problemas para a tradução, conforme ela aponta, são as especificidades culturais, como nomes de lugares, pessoas e instituições, ou mesmo sistemas de medidas ou moedas correntes; símiles e comparações com conceitos familiares na língua de partida, mas que não são familiares na língua de chegada; a relevância (maior ou menor) de certas informações para o público-alvo da língua de chegada; e os diálogos que estes textos estabelecem com outros discursos públicos na língua de partida, inexistentes na de chegada.

Pela riqueza de informações que apresenta, pela maneira equilibrada de dosar teoria e prática da tradução, pela forma como esse conteúdo é distribuído e organizado sistematicamente ao longo dos capítulos - de maneira clara e didática, mas, ainda assim, instigante e aprofundada - e, especialmente, pela sólida base de Linguística de Corpus que fundamenta as escolhas teóricas e os exemplos do livro, Scientific and Technical Translation é uma obra que tem tudo para se tornar um grande marco e uma obra de referência para o ensino da tradução técnica e científica em nível superior. A obra de Olohan preenche uma 
grande lacuna no cenário acadêmico dos estudos da tradução, que nem sempre tem dado a devida importância à tradução especializada. Mas como bem demonstra a autora nesta obra, é uma atenção que a tradução especializada merece ter.

\section{REFERÊNCIAS BIBLIOGRÁFICAS}

AZENHA JÚNIOR, J. Tradução técnica e condicionantes culturais: primeiros passos para um estudo integrado. São Paulo: Humanitas/FFLCH/USP, 1999.

BAKER, M. Corpus Linguistics and Translation Studies: Implications and Applications. In: BAKER, Mona; FRANCIS, Gill; TOGNINI-BONELLI, Elena (eds). Text and Technology: In Honour of John Sinclair. Amsterdam/Philadelphia: Benjamins, 1993, p. 233-250.

BOWKER, L.; PEARSON, J. Working with Specialized Language: A Practical Guide to Using Corpora. London and New York: Routledge, 2002.

BYRNE, J. Scientific and Technical Translation Explained. Manchester: St. Jerome Publishing, 2012.

182 Technical Translation: Usability Strategies for Translating Technical Documentation. Dordrecht, Netherlands: Springer, 2006.

KILGARRIFF, A.; BAISA, V.; BUŠTA, J. et al. Lexicography ASIALEX 1: 7, 2014. doi:10.1007/s40607-014-0009-9.

KINGSCOTT, G. Technical Translation and Related Disciplines. Perspectives: Studies in Translatology 10 (4), 2002, p. 247-255.

OLOHAN, M. Introducing Corpora in Translation Studies. London: Routledge, 2004.

ROGERS, M. Specialised translation: Shedding the 'Non-Literary' Tag. Hampshire: Palgrave Macmillan, 2015.

PEARSON, Jennifer. Terms in Context. Amsterdam and Philadelphia: John Benjamins, 1998.

PINCHUCK, I. Scientific and Technical Translation. London: André Deutsch Ltd., 1977.

SWALES, J. M. English as Tyrannosaurus rex. World Englishes 16(3), 1997, p. 373-382. doi: 10.1111/1467-971X.00071.

WRIGHT, C. Literary Translation. New York: Routledge, 2016. 
RECEBIDO EM: 05/05/2017

ACEITO EM: 31/05/2017

PUBLICADO EM: Junho de 2017

\footnotetext{
${ }^{1}$ Elisa Duarte TEIXEIRA - Bacharel em Letras - Linguística (1997) pela Universidade de São Paulo (USP). Mestre (2004) e Doutora (2008) em Estudos Linguísticos e Literários em Inglês pela mesma universidade. É Professora Adjunta do Bacharelado em Letras - Tradução/Inglês na Universidade de Brasília (UnB).

Brasília, Distrito Federal, Brasil.

Lattes: http://lattes.cnpq.br/2718046708360707 E-mail: elisadut.unb@gmail.com

2 "become reflective professionals who can behave responsibly towards clients, apply specialist knowledge and exercise autonomous thought and judjement in [their] work".
} 